\title{
Skin sparing mastectomy and robotic latissimus dorsi-flap reconstruction through a single incision
}

\author{
Gilles Houvenaeghel ${ }^{1 *}$ (D), Marie Bannier ${ }^{2}$, Sandrine Rua ${ }^{2}$, Julien Barrou², Mellie Heinemann, Eric Lambaudie ${ }^{1}$ and \\ Monique Cohen ${ }^{2}$
}

\begin{abstract}
Background: Robotic latissimus dorsi-flap reconstruction (RLDFR) after skin-sparing mastectomy (SSM) for breast cancer (BC) has been performed through a single nipple incision. We report results of SSM with RLDFR, mainly with analysis of feasibility, morbidity, indications, and technique standardization.

Methods: We determined characteristics of patients, previous treatment of $\mathrm{BC}$, and type of reconstruction. Surgical technique, duration of surgery, and complication rate were reported according to three successive periods: P1-3.

Results: Forty RLDFR, with breast implant for 16 patients, with previous breast radiotherapy in 30\% had been performed. In logistic regression, factors significantly associated with duration of surgery $\geq 300$ min were P2 (OR $0.024, p=0.004)$ and P3 (OR 0.012, $p=0.004$ ) versus P1. The median mastectomy weight was $330 \mathrm{~g}$ and $460 \mathrm{~g}$ for $\mathrm{BMI}<$ and $\geq 23.5$ ( $p=0.025)$. Length of hospitalization was 4 days. Total complication rate was $20 \%(8 / 40)$ : seven breast complications (four re-operations) and one RLDF complication with re-operation. Periods were significantly predictive of complications ( $p=0.045$ ).

Conclusion: SSM with RLDFR is feasible, safe, and reproducible. We reported a decrease of duration of surgery, length of post-operative hospitalization, and complication rate.
\end{abstract}

Keywords: Breast reconstruction, Latissimus dorsi-flap, Robotic surgery

\section{Introduction}

Development of robotic surgery since several years was very important for prostatic cancer, gynecologic cancer, colo-rectal cancer, and thoracic and thyroid surgery [13]. Endoscopic non-robotic latissimus dorsi-flap breast reconstruction (LDFR) has been reported in several studies [4-9].

Very few experiences were reported in the field of breast surgery, with a small number of series including very few patients on robotic mastectomy or LDFR [1014]. Nipple-sparing mastectomy (NSM) with immediate robotic latissimus dorsi-flap (RLDF) reconstruction has been reported in seven patients in Selber et al.'s study

\footnotetext{
* Correspondence: houvenaeghelg@ipc.unicancer.fr

${ }^{1}$ Department of Surgical Oncology, Paoli Calmettes Institute and CRCM,

CNRS, INSERM, Aix Marseille Université, 232 Bd de Sainte Marguerite, 13009

Marseille, France

Full list of author information is available at the end of the article
}

[10] and in four cases in Chung et al.'s study [12]. Skinsparing mastectomy (SSM) with LDF reconstruction was reported in 17 patients for delayed-immediate breast reconstruction after SSM and placement of a tissue expander [13] and in one patient for immediate breast reconstruction with $3 \mathrm{D}$ endoscopy using another incision than areolar incision [15]. In a recent French prospective cohort study, Immediate breast reconstruction (IBR) was performed with LDFR in $46.9 \%$ of cases (24.3\% combined with an implant), with implant in $46.5 \%$, and rectus abdominis musculo-cutaneous flap in $6.6 \%$ [16]. The aim of this study was to report results of SSM with robotic LDFR performed during 29 months, through the analysis of feasibility, morbidity, indications, and standardization of patient positioning and operative technique.

(C) The Author(s). 2019 Open Access This article is distributed under the terms of the Creative Commons Attribution 4.0 International License (http://creativecommons.org/licenses/by/4.0/), which permits unrestricted use, distribution, and reproduction in any medium, provided you give appropriate credit to the original author(s) and the source, provide a link to the Creative Commons license, and indicate if changes were made. The Creative Commons Public Domain Dedication waiver (http://creativecommons.org/publicdomain/zero/1.0/) applies to the data made available in this article, unless otherwise stated. 


\section{Material methods}

A prospective cohort of patients undergoing SSM and robotic latissimus dorsi-flap reconstruction (RLDFR) over a period of 29 months (March 2016 to July 2018) was analyzed. All patients agreed to surgery with robotic assistance and received information on the procedure. The study protocol was approved by our institutional ethical committee.

We analyzed patient characteristics (age, body mass index (BMI), tobacco use, diabetes, ASA score, breast volume), previous treatment for breast cancer (BC) (sentinel lymph node biopsy (SLNB), axillary lymph node dissection (ALND), neo-adjuvant chemotherapy (NAC), previous breast radiotherapy), primary breast cancer (BC) or local recurrence, and type of reconstruction (LDFR with or without breast implant).

Surgical technique using da Vinci $\mathrm{Si}^{\circledR}$ Surgical System SI or XI (Intuitive Surgical, Sunnyvale, CA), number of trocars, skin incision, and duration of anesthesia and surgery were recorded according to period of treatment and associated surgical procedures (breast implant, LDFR, ALND, and contra-lateral breast surgery). Duration of anesthesia was defined as time from anesthesia induction to tracheal extubation and duration of surgery as time from skin incision to the end of skin suture including all associated procedures and changes in patient positioning. Three periods were established: P1 (year 2016), P2 (year 2017), and P3 (year 2018).

Complication rate was determined using Clavien-Dindo grading [17]. Re-operation rate, type of complication, and number of post-operative hospitalization days were reported.

\section{Statistics}

Main characteristics were reported using median, mean, and $95 \%$ confidence interval (CI95) for quantitative criteria. Comparisons were performed using $\chi^{2}$ for categorical variables, $t$ test or Anova for continuous variables, and logistic binary regression with odds ratios, CI95 and, $p$ value with $\mathrm{SPSS}^{\oplus}$ software version 16.0. We considered $p$ value $\leq 0.05$ as significant result.

\section{Results}

During the study period of 29 months, 119 patients were operated for breast surgery and/or RLDFR, 117 with da Vinci robot, and 2 with 3D endoscopy. Among these patients, we analyzed 40 patients with the same surgical procedure, SSM and RLDFR, performed by the same surgeon. Breast reconstruction was performed in 25 patients with autologous LDF associated with breast implant in 7 patients and in 15 patients with nonautologous LDF (without fat around LDF) associated with breast implant in 9 patients. The number of patients was 11,18 , and 11 , respectively, for periods $\mathrm{P} 1-$
P3. Chest sizes were $85,90,95,100$, and > 100, respectively, in 4, 10, 17, 6, and 3 patients. Patients' characteristics are reported in Tables 1 and 2 .

\section{Indications and type of reconstruction}

Twelve patients had previous breast radiotherapy (30\%, 12/40) including seven patients with SSM after NAC and radiotherapy $(17.5 \%, 7 / 40)$. SSM was performed for five local $\mathrm{BC}$ recurrences with previous radiotherapy and 35 primary BC: 11 ductal carcinomas in situ (DCIS) and 29 invasive $\mathrm{BC}$.

RLDFR with breast implant was performed in $40 \%$ of patients (16/40) (Table 3), in 58.3\% (7/12) after previous radiotherapy. Mastectomy weight, breast cup size, and BMI according to the type of reconstruction are reported in Table 2.

Robotic breast surgery was indicated in selected cases during the study period: 92 RLDF for IBR (40 SSM and 52 nipple sparing mastectomy) among 437 IBR (21\%) and among 1193 patients who required a total mastectomy (7.7\%). A selection of patients for RLDF was made according to patient's wishes to avoid dorsal scar and to offer IBR without implant for patients who do not want implant breast reconstruction.

\section{Surgery: (Fig. 1)}

All patients were either first positioned in dorsal decubitus for SSM followed by a side decubitus for RLDFR. The anterior border of the LD muscle and the inferior mammary fold were designed and marked before incision. Incision around the nipple areolar complex was performed for SSM, and LDF dissection was performed in 33 patients through this incision and in 7 patients through a short axillar incision more often during P1 and P2 (Table 1).

The beginning of the dissection for sub-cutaneous plan of LD muscle and a limited dissection under the incision along the anterior axillary line in order to introduced one robotic trocar about 6-7 cm under axillar basin (at the inferior mammary fold level) was performed.

Then, a Gelpoint ${ }^{\odot}$ path single site device (Applied Medical) was inserted through the incision with two robotic trocars and one trocar for an Airseal $^{\circ}$ device insufflation (Applied Medical) also used by the assistant surgeon when necessary. We operated under low pressure $(7 \mathrm{mmHg})$. Depending of the breast side, we inserted monopolar scissors and bipolar forceps into up and down robotic trocars with $0^{\circ}$ camera in the middle robotic trocar.

Robotic surgery started with a superficial dissection of LD muscle from the middle of the muscle to the inferior part $(5-6 \mathrm{~cm}$ under the inferior mammary fold) and to the superior part with a total section of the tendinous 
Table 1 Characteristics of all patients and according to periods of treatment

\begin{tabular}{|c|c|c|c|c|c|c|c|c|c|c|}
\hline \multirow{2}{*}{ Population } & & \multirow[b]{2}{*}{$n$} & \multirow[b]{2}{*}{$\%$} & \multicolumn{2}{|c|}{ P1-2016 } & \multicolumn{2}{|c|}{ P2-2017 } & \multicolumn{2}{|c|}{ P3-2018 } & \multirow{2}{*}{$\begin{array}{l}x^{2} \\
p\end{array}$} \\
\hline & & & & $n$ & $\%$ & $n$ & $\%$ & $n$ & $\%$ & \\
\hline Number patients & & 40 & & 11 & 27.5 & 18 & 45.0 & 11 & 27.5 & \\
\hline Primary BC & & 35 & 87.5 & 7 & 63.6 & 17 & 94.4 & 11 & 100 & 0.017 \\
\hline Local recurrence & & 5 & 12.5 & 4 & 36.4 & 1 & 5.6 & 0 & 0 & \\
\hline Tobacco & & 9 & 22.5 & 5 & 45.5 & 3 & 16.7 & 1 & 9.1 & 0.090 \\
\hline Diabete & & 3 & 7.5 & 2 & 18.2 & 1 & 5.6 & 0 & 0 & 0.247 \\
\hline \multirow[t]{3}{*}{ ASA } & 1 & 18 & 45.0 & 5 & 45.5 & 6 & 33.3 & 7 & 63.6 & 0.252 \\
\hline & 2 & 21 & 52.5 & 5 & 45.5 & 12 & 66.7 & 4 & 36.4 & \\
\hline & 3 & 1 & 2.5 & 1 & 9.1 & 0 & 0 & 0 & 0 & \\
\hline \multirow[t]{3}{*}{ Breast size } & $A-B$ & 15 & 37.5 & 2 & 18.2 & 8 & 44.4 & 5 & 45.4 & 0.20 \\
\hline & C & 18 & 45.0 & 5 & 45.5 & 9 & 50.0 & 4 & 36.4 & \\
\hline & $D-F$ & 7 & 17.5 & 4 & 36.3 & 1 & 5.6 & 2 & 18.2 & \\
\hline \multirow[t]{2}{*}{ Prosthesis size } & $<300$ & 5 & 29.4 & 4 & 40.0 & 1 & 16.7 & 0 & 0 & 0.50 \\
\hline & $\geq 300$ & 12 & 70.6 & 6 & 60.0 & 5 & 83.3 & 1 & 100 & \\
\hline \multirow[t]{2}{*}{ Previous radiotherapy } & Yes & 12 & 30.0 & 6 & 54.5 & 4 & 22.2 & 2 & 18.2 & 0.10 \\
\hline & No & 28 & 70.0 & 5 & 45.5 & 14 & 77.8 & 9 & 81.8 & \\
\hline Neo adjuvant chemotherapy & & 7 & 17.5 & 2 & 18.2 & 3 & 16.7 & 2 & 18.2 & 0.992 \\
\hline \multirow[t]{4}{*}{ Reconstruction } & Autologous LDF & 18 & 45.0 & 2 & 18.2 & 12 & 66.7 & 4 & 36.4 & $<0.0001$ \\
\hline & Non-autologous LDF & 6 & 15.0 & 0 & 0 & 0 & 0 & 6 & 54.5 & \\
\hline & LDF + implant & 9 & 22.5 & 4 & 36.4 & 5 & 27.8 & 0 & 0 & \\
\hline & Autologous LDF + implant & 7 & 17.5 & 5 & 45.5 & 1 & 5.6 & 1 & 9.1 & \\
\hline \multirow[t]{2}{*}{ Incision for RLDFR } & Axillar & 7 & 17.5 & 3 & 27.3 & 3 & 16.7 & 1 & 9.1 & 0.490 \\
\hline & Areolar & 33 & 82.5 & 8 & 72.7 & 15 & 83.3 & 10 & 90.9 & \\
\hline \multirow[t]{2}{*}{$B C$} & Invasive & 29 & 72.5 & 8 & 72.7 & 14 & 77.8 & 7 & 63.6 & 0.710 \\
\hline & DCIS & 11 & 27.5 & 3 & 27.3 & 4 & 22.2 & 4 & 36.4 & \\
\hline \multirow[t]{3}{*}{ Number of surgical procedures } & 2 & 21 & 52.5 & 2 & 18.2 & 12 & 66.7 & 7 & 63.6 & 0.070 \\
\hline & 3 & 16 & 40.0 & 7 & 63.6 & 6 & 33.3 & 3 & 27.3 & \\
\hline & 4 & 3 & 7.5 & 2 & 18.2 & 0 & 0 & 1 & 9.1 & \\
\hline \multirow[t]{2}{*}{ da Vinci system } & $\mathrm{SI}$ & 17 & 42.5 & 11 & 100 & 6 & 33.3 & 0 & 0 & $<0.0001$ \\
\hline & $X I$ & 23 & 57.5 & 0 & 0 & 12 & 66.7 & 11 & 100 & \\
\hline \multirow[t]{2}{*}{ Number of arms } & 2 & 29 & 72.5 & 3 & 27.3 & 15 & 83.3 & 11 & 100 & $<0.0001$ \\
\hline & 3 & 11 & 27.5 & 8 & 72.7 & 3 & 16.7 & 0 & 0 & \\
\hline \multirow[t]{2}{*}{ Hospitalization days } & $<4$ days & 13 & 32.5 & 0 & 0 & 8 & 44.4 & 5 & 45.5 & 0.026 \\
\hline & $\geq 4$ days & 27 & 67.5 & 11 & 100 & 10 & 55.6 & 6 & 54.5 & \\
\hline \multirow[t]{2}{*}{ Time of surgery } & $<300 \mathrm{mn}$ & 26 & 65.0 & 1 & 9.1 & 15 & 83.3 & 10 & 90.9 & $<0.0001$ \\
\hline & $\geq 300 \mathrm{mn}$ & 14 & 35.0 & 10 & 90.9 & 3 & 16.7 & 1 & 9.1 & \\
\hline \multirow[t]{2}{*}{ Time of anesthesia } & $<382 \mathrm{mn}$ & 26 & 65.0 & 2 & 18.2 & 14 & 77.8 & 10 & 90.9 & 0.001 \\
\hline & $\geq 382 \mathrm{mn}$ & 14 & 35.0 & 9 & 81.8 & 4 & 22.2 & 1 & 9.1 & \\
\hline \multirow[t]{2}{*}{ BMl } & $<23.5$ & 17 & 42.5 & 5 & 45.5 & 7 & 38.9 & 5 & 45.5 & 0.916 \\
\hline & $\geq 23.5$ & 23 & 57.5 & 6 & 54.5 & 11 & 61.1 & 6 & 54.5 & \\
\hline Previous contra lateral BC & No & 36 & 90.0 & 8 & 72.7 & 18 & 100 & 10 & 92.9 & 0.059 \\
\hline & Yes & 4 & 10.0 & 3 & 27.3 & 0 & 0 & 1 & 9.1 & \\
\hline Previous homolateral $\mathrm{BCT}$ & No & 21 & 52.5 & 5 & 45.5 & 10 & 55.6 & 6 & 54.5 & 0.859 \\
\hline & Yes & 19 & 47.5 & 6 & 54.5 & 8 & 44.4 & 5 & 45.5 & \\
\hline
\end{tabular}


Table 1 Characteristics of all patients and according to periods of treatment (Continued)

\begin{tabular}{|c|c|c|c|c|c|c|c|c|c|c|}
\hline \multirow{2}{*}{ Population } & & \multirow[b]{2}{*}{$n$} & \multirow[b]{2}{*}{$\%$} & \multicolumn{2}{|c|}{ P1-2016 } & \multicolumn{2}{|c|}{ P2-2017 } & \multicolumn{2}{|c|}{ P3-2018 } & \multirow{2}{*}{$\begin{array}{l}x^{2} \\
p\end{array}$} \\
\hline & & & & $n$ & $\%$ & $n$ & $\%$ & $\bar{n}$ & $\%$ & \\
\hline \multirow[t]{2}{*}{ Contra lateral breast surgery } & No & 38 & 95.0 & 11 & 100 & 17 & 94.4 & 10 & 90.9 & 0.613 \\
\hline & Yes & 2 & 5.0 & 0 & 0 & 1 & 5.6 & 1 & 9.1 & \\
\hline
\end{tabular}

$B M I$ body mass index, SI da Vinci SI system, XI da Vinci XI system, LDF latissimus dorsi-flap, NSM nipple-sparing mastectomy, RLDFR robotic latissimus dorsi-flap reconstruction, $B C$ breast cancer, $D C I S$ ductal carcinomas in situ, $B C T$ breast-conserving therapy

insertion. Then, we performed dissection underneath the LD muscle from the middle to the inferior part and to the level of vascular pedicle. The section of LD muscle was performed with monopolar scissors for posterior dorsal insertions, then at the inferior part of dissection, with progressive mobilization of muscle. Two drains were placed through the inferior infra-centimetric scar for the dorsal area and one for mastectomy.

Seventeen rights and 23 left SSM were realized. Robotic procedures were performed using SI daVinci system in 17 patients and XI system in 23 patients. We used 3 arms for 11 patients and 2 arms for 29 patients (72.5\%): 3 arms 8/11 (72.37\%) during 2016, 3/18 (16.7\%) during 2017, and 0/11 during $2018(p<0.0001)$.

Concomitant with other surgical procedures, in 19 cases (47.5\%), a previous partial ipsilateral breast resection had been performed. Axillary surgery was performed concomitantly in 23 cases (16 SLNB, 5 ALND, and 2 SLNB with ALND) (5 previous ALND for 5 local recurrences). A contra-lateral breast surgery was performed during the same operation in $2(5 \%)$ patients.

\section{Duration of procedure}

Median anesthesia duration was $353 \mathrm{~min}$ and median surgery duration was $290 \mathrm{~min}$ (Table 2). The duration of the surgery for the successive patients is reported in Fig. 2. The number of surgical procedures performed (LDFR, breast implant, ALND, contra-lateral breast surgery) was $\geq 3$ for 19 patients (47.5\%) including 3 patients with 4 procedures. BMI was $\geq 23.5$ in $57.5 \%$ of patients $(23 / 40)$.

In univariate analysis, duration of surgery were significantly different according to robot system used $(p=0.002)$, period $\mathrm{P} 1$ versus $\mathrm{P} 2-3 \quad(p<0.0001$ and non-significant between $\mathrm{P} 2$ and $\mathrm{P} 3$ ), number of robotic arms used (> for 3 arms: $p<0.0001$ ), number of surgical procedures $>2(p=0.015)$ (non-significant for $\mathrm{BMI}<$ or $\geq 23.5: p=0.790$ ). In binary logistic regression including the 3 study periods and number of surgical procedures $(>$ or $\leq 2)$, significant factors of duration of surgery $\geq 300 \mathrm{mn}$ were: $\mathrm{P} 2$ with a reduction in duration of surgery (OR 0.024, CI 0.002-0.298, $p=0.004$ ) and P3 (OR: 0.012, CI $0.001-0.234, \mathrm{p}=0.004$ ) versus $\mathrm{P} 1$ (number of surgical procedures: non-significant: $p=0.634$ ). A strong correlation was observed between periods and robot system used and number of robotic arms.
In univariate analysis, the duration of anesthesia were significantly different according to the robot system used $(p<0.0001)$, number of robotic arms ( $>3$ arms, $p<$ $0.0001)$, number of surgical procedures $>2(p=0.012)$, and period P1 versus P2-3 $(p<0.0001$ and significance between P2 and P3, $p=0.043)$. In binary logistic regression including the three periods and the number of surgical procedures $(>$ or $\leq 2$ ), duration of anesthesia $<$ or $\geq$ $382 \mathrm{mn}$ differed significantly for the following periods: P2 (OR 0.062, CI 0.008-0.506, $p=0.009$ ) and P3 (OR 0.022 , CI $0.001-0.325, p=0.006$ ) versus $\mathrm{P} 1$ (number of surgical procedures-non-significant, $p=0.955$ ).

Decrease rate of mean duration of surgery was 31.9\% and decrease rate of mean duration of anesthesia was $28.5 \%$ from P1 to P3.

\section{Pathologic results}

The median mastectomy weight was $401 \mathrm{~g}: 330 \mathrm{~g}$ (CI 251-377, mean 314, range 100-527) for BMI $<23.5$ and $460 \mathrm{~g}$ (CI 378-696, mean 537, range 72-1600) for BMI $\geq$ 23.5 , respectively $(p=0.025)$. Median breast implant volume was $340 \mathrm{cc}$ (range 225-395).

The median size of invasive $\mathrm{BC}$ was $25 \mathrm{~mm}$ (mean 42.3, CI 28.6-56.1, range 0.7-130) with 15 multifocal BC (20 ductal, 10 lobular, 1 other type, and 9 DCIS). Median DCIS size was $50.0 \mathrm{~mm}$ (mean 54.2, CI 22.286.2, range 1-120).

\section{Post-operative treatment}

Six patients (21.4\%) underwent post-mastectomy radiotherapy among 28 patients without previous radiotherapy, 8 patients received adjuvant chemotherapy, 28 patients endocrine therapy, and 3 patients received trastuzumab.

\section{Post-operative outcome}

The median length of post-operative hospitalization was 4 days (Table 2): 13 patients $<4$ days $(32.5 \%)$ and 27 patients $\geq 4$ days. Hospital stay $\geq 4$ days was significantly associated with periods P1 versus P2-3 $(11 / 11$ for P1 and $16 / 29$ for P2-3, $p=0.006)$, robot system used $(p=0.002)$, and type of reconstruction $(p=0.022)$. Others criteria analyzed were not significant: mastectomy weight, duration of anesthesia and surgery, previous radiotherapy ( $\geq 4$ days $17 / 28$ without and 10/12 with radiotherapy, non-significant), 
Table 2 Characteristics of patients and surgery

\begin{tabular}{|c|c|c|c|c|c|}
\hline Population & All patients & Median & Mean & Cl 95\% & Range \\
\hline Age & & 64.0 & 61.2 & $40.8-81.6$ & $39-83$ \\
\hline Mastectomy weight & & 358 & 445 & $345-546$ & $72-1600$ \\
\hline BMI & & 24.5 & 25.4 & $23.9-26.9$ & $18.3-38.0$ \\
\hline Duration of surgery & & 290 & 298 & $276-321$ & 195-495 \\
\hline Duration of anesthesia & & 353 & 364 & $341-387$ & $249-540$ \\
\hline Hospital stay duration & & 4 & 4.38 & $3.89-4.86$ & $2.0-8.0$ \\
\hline \multirow[t]{3}{*}{ Duration of surgery } & P1 & 372 & 373 & $328-419$ & $235-495$ \\
\hline & P2 & 271 & 280 & $257-302$ & $215-410$ \\
\hline & P3 & 258 & 254 & $222-286$ & $195-343$ \\
\hline \multirow[t]{3}{*}{ Duration of anesthesia } & P1 & 428 & 438 & $393-483$ & $313-540$ \\
\hline & P2 & 355 & 351 & $328-373$ & $276-457$ \\
\hline & P3 & 323 & 313 & $281-345$ & 249-404 \\
\hline \multirow[t]{2}{*}{ Duration of surgery } & $\mathrm{SI}$ & 334 & 336 & $297-376$ & 215-495 \\
\hline & $X I$ & 266 & 270 & $248-292$ & $195-410$ \\
\hline \multirow[t]{2}{*}{ Duration of anesthesia } & $\mathrm{SI}$ & 403 & 410 & $376-444$ & $313-540$ \\
\hline & $X I$ & 331 & 330 & $307-353$ & $249-457$ \\
\hline \multirow[t]{3}{*}{ Duration of surgery } & 2 surgical procedures & 258 & 273 & $245-301$ & $195-410$ \\
\hline & 3 surgical procedures & 301 & 318 & $281-354$ & 215-495 \\
\hline & 4 surgical procedures & 420 & 372 & $167-577$ & $277-420$ \\
\hline \multirow[t]{4}{*}{ Duration of surgery } & Autologous LDF & 265 & 274 & $243-306$ & $195-410$ \\
\hline & Non autologous LDF & 262 & 268 & $225-312$ & 219-343 \\
\hline & LDF + implant & 325 & 342 & $270-413$ & 215-495 \\
\hline & Autologous LDF + implant & 334 & 330 & $293-366$ & $270-372$ \\
\hline \multirow[t]{4}{*}{ Duration of anesthesia } & Autologous LDF & 339 & 341 & $308-374$ & $249-506$ \\
\hline & Non-autologous LDF & 327 & 327 & $276-378$ & $252-404$ \\
\hline & LDF + implant & 409 & 412 & $351-474$ & $294-540$ \\
\hline & Autologous LDF + implant & 403 & 394 & $353-435$ & $342-451$ \\
\hline \multirow[t]{4}{*}{ Hospital stay duration } & Autologous LDF & 4 & 3.83 & $3.12-4.54$ & $2.0-7.0$ \\
\hline & Non-autologous LDF & 3 & 3.33 & $2.79-3.88$ & $3.0-4.0$ \\
\hline & LDF + implant & 5 & 4.89 & $3.99-5.79$ & $3.0-7.0$ \\
\hline & Autologous LDF + implant & 6 & 6.0 & $4.81-7.19$ & $4.0-8.0$ \\
\hline \multirow[t]{4}{*}{ BMl } & Autologous LDF & 25.3 & 26.6 & $23.8-29.4$ & $18.3-38.0$ \\
\hline & Non-autologous LDF & 21.7 & 22.3 & $20.2-24.4$ & $19.7-25.3$ \\
\hline & LDF + implant & 26.2 & 26.1 & $23.3-28.9$ & $20.3-31.6$ \\
\hline & Autologous LDF + implant & 23.1 & 24.2 & $21.3-27.2$ & $20.8-28.6$ \\
\hline \multirow[t]{4}{*}{ Mastectomy weight } & Autologous LDF & 340 & 503 & 298-708 & $100-1600$ \\
\hline & Non-autologous LDF & 225 & 238 & $77-400$ & $72-423$ \\
\hline & LDF + implant & 370 & 409 & $281-536$ & $201-696$ \\
\hline & Autologous LDF + implant & 488 & 492 & $342-641$ & $263-778$ \\
\hline \multirow[t]{3}{*}{ Hospital stay duration } & P1 & 6 & 5.64 & $5.02-6.26$ & $4.0-7.0$ \\
\hline & P2 & 4 & 3.83 & $3.19-4.48$ & $2.0-7.0$ \\
\hline & P3 & 4 & 4.0 & $2.88-5.12$ & $2.0-8.0$ \\
\hline
\end{tabular}

$B M I$ body mass index, SI da Vinci SI system, $X I$ da Vinci XI system, $P$ (1-3) period (1-3), LDF latissimus dorsi-flap 
Table 3 Results according to reconstruction type

\begin{tabular}{|c|c|c|c|c|c|c|}
\hline & & \multicolumn{2}{|c|}{ RLDF without implant } & \multicolumn{2}{|c|}{ RLDF + implant } & \multirow{2}{*}{$\frac{x^{2}}{p}$} \\
\hline & & $n$ & $\%$ & $n$ & $\%$ & \\
\hline \multirow[t]{2}{*}{ Age } & $\leq 50$ years & 8 & 33.3 & 3 & 18.8 & \multirow[t]{2}{*}{0.261} \\
\hline & $>50$ years & 16 & 66.7 & 13 & 81.2 & \\
\hline \multirow[t]{3}{*}{ Periods } & P1 & 2 & 8.3 & 9 & 56.2 & \multirow[t]{6}{*}{0.002} \\
\hline & P2 & 12 & 50.0 & 6 & 37.5 & \\
\hline & P3 & 10 & 41.7 & 1 & 6.2 & \\
\hline \multirow[t]{3}{*}{ Breast cup size } & $A-B$ & 12 & 50.0 & 3 & 18.8 & \\
\hline & $C$ & 9 & 37.5 & 9 & 56.2 & \\
\hline & $\geq D$ & 3 & 12.5 & 4 & 25.0 & \\
\hline \multirow[t]{2}{*}{ BMI } & $<23.5$ & 10 & 41.7 & 7 & 43.8 & \multirow[t]{2}{*}{0.576} \\
\hline & $\geq 23.5$ & 14 & 58.3 & 9 & 56.2 & \\
\hline Primary BC & & 23 & 95.8 & 12 & 75.0 & \multirow[t]{4}{*}{0.073} \\
\hline Local recurrence & & 1 & 4.2 & 4 & 25.0 & \\
\hline \multirow[t]{2}{*}{ Previous radiotherapy } & No & 19 & 79.2 & 9 & 56.2 & \\
\hline & Yes & 5 & 20.9 & 7 & 43.8 & \\
\hline \multirow[t]{2}{*}{ Hospitalization days } & $<4$ days & 12 & 50.0 & 1 & 6.2 & \multirow[t]{2}{*}{0.004} \\
\hline & $\geq 4$ days & 12 & 50.0 & 15 & 93.8 & \\
\hline \multirow[t]{2}{*}{ Duration of surgery } & $<305 \mathrm{mn}$ & 20 & 83.3 & 6 & 37.5 & \multirow[t]{2}{*}{0.004} \\
\hline & $\geq 305 \mathrm{mn}$ & 4 & 16.7 & 10 & 62.5 & \\
\hline \multirow[t]{2}{*}{ Duration of anesthesia } & $<382 \mathrm{mn}$ & 19 & 79.2 & 7 & 43.8 & \multirow[t]{2}{*}{0.025} \\
\hline & $\geq 382 \mathrm{mn}$ & 5 & 20.8 & 9 & 56.2 & \\
\hline \multirow[t]{3}{*}{ Mastectomy weight } & $\geq 330 \mathrm{~g}$ & 12 & 52.2 & 4 & 25.0 & \multirow[t]{3}{*}{0.085} \\
\hline & $>330 \mathrm{~g}$ & 11 & 47.8 & 12 & 75.0 & \\
\hline & & Median & Cl 95\% & Median & Cl 95\% & \\
\hline \multicolumn{2}{|l|}{ Age } & 58 & $51-63$ & 65 & $53-67$ & \\
\hline \multicolumn{2}{|l|}{ Mastectomy weight } & 329 & $280-611$ & 439 & $357-532$ & \\
\hline \multicolumn{2}{|l|}{ BMl } & 24.0 & $23.5-28.0$ & 25.6 & $23.4-27.1$ & \\
\hline \multicolumn{2}{|l|}{ Hospitalization days } & 4 & $3.18-4.30$ & 5 & $4.68-6.07$ & \\
\hline
\end{tabular}

$B M I$ body mass index, $B C$ breast cancer, $R L D F$ robotic latissimus dorsi-flap

mastectomy for primary $\mathrm{BC}$ or local recurrence, BMI, age, and number of surgical procedures. In binary logistic regression, any factor was significant for postoperative hospitalization $\geq 4$ days.

The total complication rate was $20 \%$ (eight patients): seven breast complications (three grade 1 and four grade 3: five hematomas, two infections) and one LDF complication (grade 3: dorsal bleeding). In univariate analysis, periods (P1, 5/11; $\mathrm{P} 2,2 / 18$; and $\mathrm{P} 3,1 / 11)$ and robot system used (SI 5/17 and XI 3/23) were significantly associated with complications (respectively, 0.045 and 0.025), and all others factors were non-significant, particularly the type of reconstruction, BMI, and duration of surgery. Five re-operations $(12.5 \%)$ were required (five grade 3 ): one for dorsal bleeding and four for breast complication (two hematomas and two infections with implant removal for one patient). Re-operations for dorsal bleeding and hematomas were made during hospitalization stay. For 14 patients, we observed dorsal seroma after drain removal that required one or several punctures. Patients were discharged before drain removal. Any conversion to an open technique for LDF dissection was required.

\section{Discussion}

The purpose of this study was to assess feasibility of RLFR through a single incision around NAC required for SSM. The reproducibility of this procedure has been illustrated by no conversion to open technique, and a short axillar incision was used in $17.5 \%$ of patients particularly at the beginning of the experience. The safety of RLDFR has been also shown with only one complication for dorsal bleeding which required re-operation performed through the same incision (2.5\%). We observed a significant decrease of the duration of surgery throughout the learning curve after 

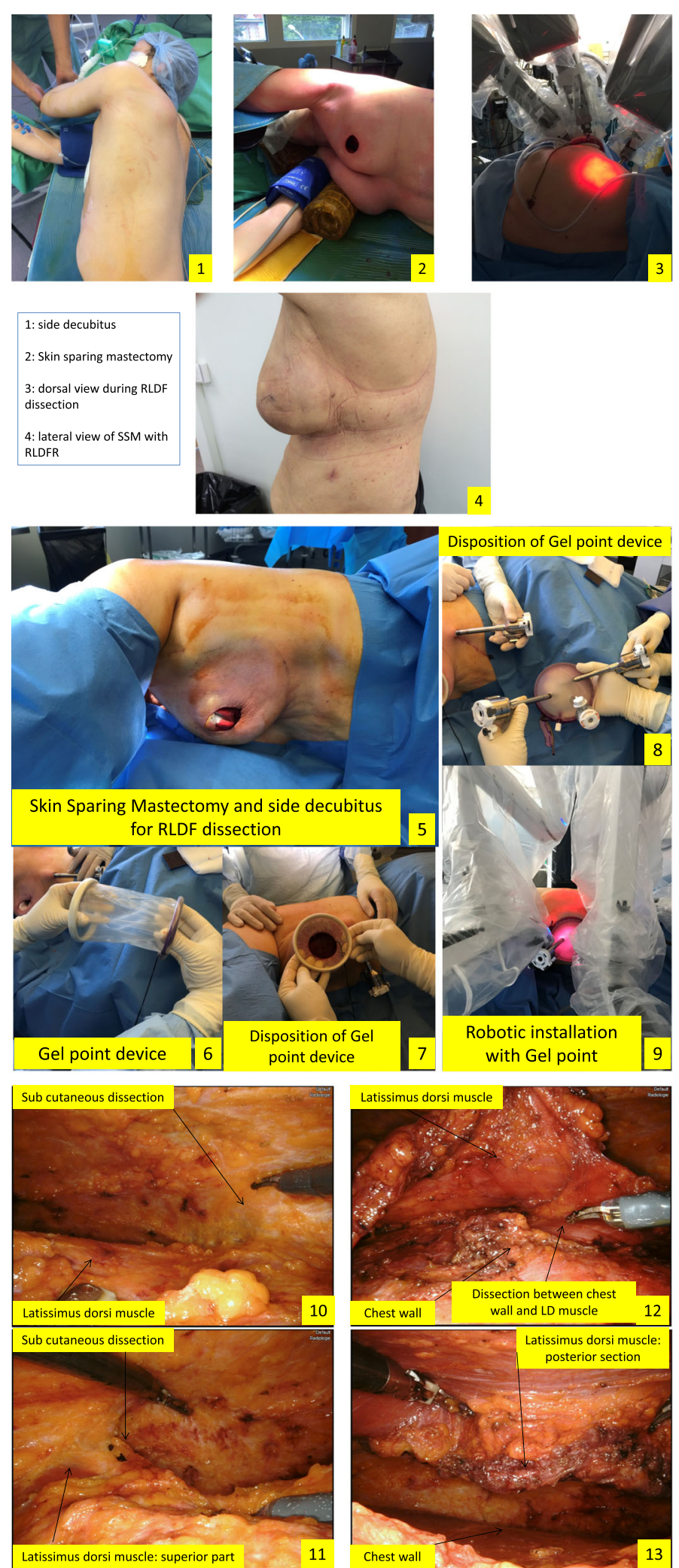

Fig. 1 Surgical procedures 


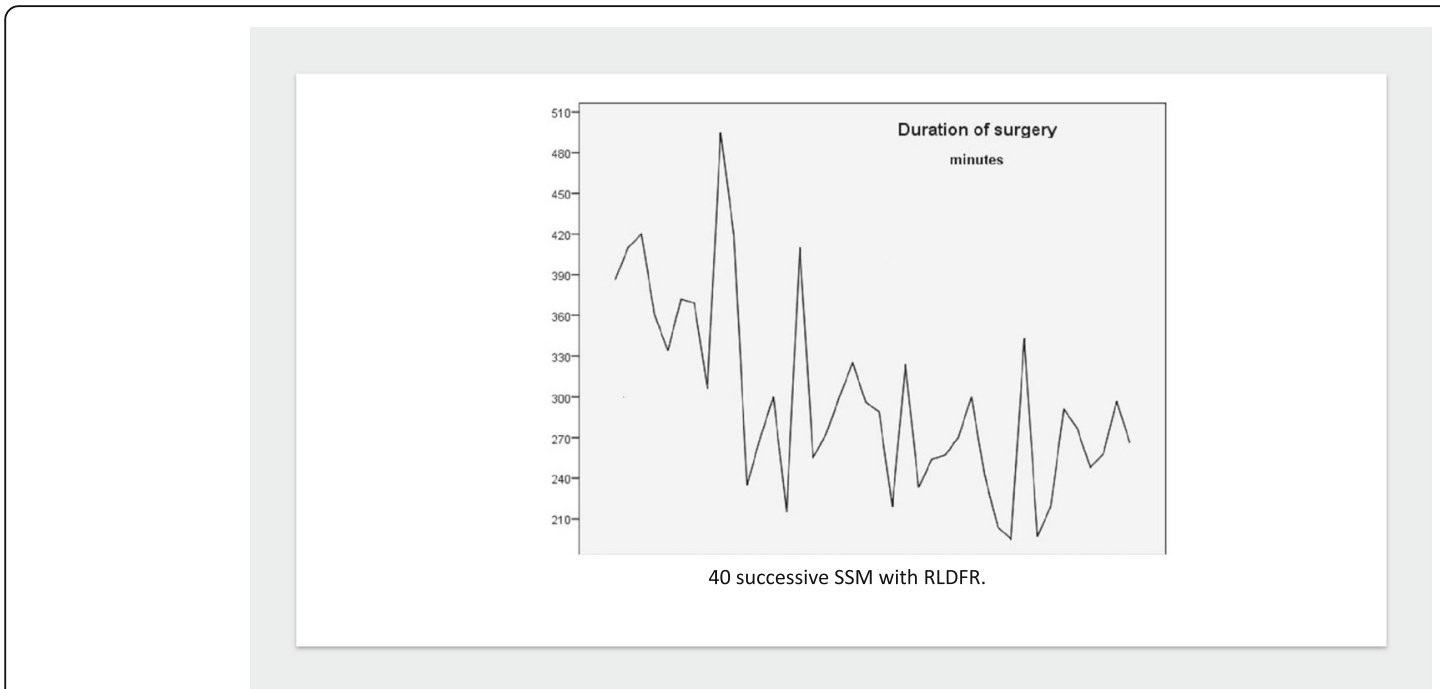

Fig. 2 Duration of surgery for 40 successive patients in chronologic order

the first period with 11 procedures. The mean duration of the whole procedure for the third period was $254 \mathrm{~min}$ and the robotic procedure currently lasts for approximately $45-60 \mathrm{~min}$.

Very few experiences were reported for RLDF immediate breast reconstruction with no more than 17 procedures [9-12]. The main differences in robotic surgical technique that should be underlined included a single incision realized around NAC for SSM and the use of a single site trocar. In Selber et al.'s study [10], seven patients were reported with RLDF reconstruction performed through an axillar incision for NSM without the use of a single site trocar. Chung et al. [12] reported 12 RLDF procedures through a 5-6-cm axillar incision without $\mathrm{CO} 2$ gas insufflation for three delayed breast reconstructions, four IBRs with NSM, and five cases of chest wall deformity. Clemens et al. [13] reported 17 RLDFRs in delayed-immediate breast reconstruction after SSM and placement of a tissue expander through anterior mastectomy incision without a single site trocar.

Endoscopic non-robotic LDFR was reported in several studies [4-8], and in 2007, Missana et al. reported a study including 52 patients [4] and more recently by others with smaller series [6-8]. Nakajima et al. [8] reported a study with 168 LDF video-assisted reconstructions but only for reconstruction after partial mastectomy. Finally, Dejode and Barranger [15] reported one case of endoscopic 3D latissimus dorsi-flap harvesting for SSM with immediate breast reconstruction.

The endoscopic approach decreases donor-site morbidity [18] but the manual control of a two dimensional in-line endoscopic camera with limited internal mobility produces an inadequate optical window around the curvature of the thorax and the rigid-tip instruments also are inadequate to work along the curvature of the thorax. The use of 3D endoscopic surgery offers a magnified view but without the seven degrees of freedom of motion at the tips of the robotic instruments.

For patients with previous radiotherapy for local recurrence or after NAC and radiotherapy [19-21], the latissimus dorsi-muscle nourishes and protects the thin skin. In these cases, RLDFR can be associated with implant according to breast size and according to patient's choice. One or several lipofillings were next proposed in order to obtain a good cosmetic result and sufficient breast volume. SSM was proposed for patients who want an IBR for whom NSM was not indicated (NAC involvement or tumor-NAC distance $<2 \mathrm{~cm}$ ). Latissimus dorsi-flap reconstruction was offered in selected cases according to patient's choice and particularly for patients who do not want reconstruction with breast implant $(60 \%$ without implant in our study). More and more centers offer breast implant reconstruction with acellular dermal matrix (ADM). However, covering the entire implant with a thin, expensive ADM is not generally feasible, and the use of ADMs also increases the risk of complications such as infection and seroma [22].

\section{Conclusion}

SSM with RLDFR is feasible, safe, and reproducible with a single incision for NAC resection. We reported with progressive learning curve a decrease of the duration of surgery, length of post-operative hospitalization, and complication rate. The robotic procedure currently lasts for approximately 45-60 min. Only one complication was related with RLDFR with re-operation for bleeding. After this technique standardization, we proposed to develop this procedure with several surgeons of our department using the double robotic console. 


\section{Acknowledgements}

Not applicable.

\section{Authors' contributions}

Data collection and analysis were performed by GH, MB, SR, JB, and MC. Others authors contributed to the literature studies analysis for discussion and participation to surgical procedures. All authors read and approved the final manuscript in its present form.

\section{Funding}

This work did not receive any specific grant from funding agencies in the public, commercial, or not-for-profit sectors.

\section{Availability of data and materials}

Administrative data and clinical data are compiled in a common database and are available to editors and peer reviewers.

\section{Ethics approval and consent to participate}

This work was approved by our institutional review board (IPC —Comité d'Orientation Stratégique).

All procedures performed in this study involving human participants were done in accordance with the French ethical standards and with the 2008 Helsinki declaration.

All included patients provided written informed consent before surgery, including the use of their data for research.

\section{Consent for publication}

Not applicable

\section{Competing interests}

The authors declare that they have no competing interests.

\section{Author details}

${ }^{1}$ Department of Surgical Oncology, Paoli Calmettes Institute and CRCM, CNRS, INSERM, Aix Marseille Université, 232 Bd de Sainte Marguerite, 13009 Marseille, France. ${ }^{2}$ Department of Surgical Oncology, Paoli Calmettes Institute, Marseille, France.

Received: 17 April 2019 Accepted: 12 September 2019

Published online: 02 November 2019

\section{References}

1. Suardi N, Larcher A, Haese A, Ficarra V, Govorov A, Buffi NM, et al. Indication for and extension of pelvic lymph node dissection during robot-assisted radical prostatectomy: an analysis of five European institutions. Eur Urol. 2014;66(4):635-43

2. Narducci F, Collinet P, Merlot B, Lambaudie E, Boulanger L, Lefebvre-Kuntz $D$, et al. Benefit of robot-assisted laparoscopy in nerve-sparing radical hysterectomy: urinary morbidity in early cervical cancer. Surg Endosc. 2013; 27(4):1237-42

3. Hudry D, Ahmad S, Zanagnolo V, Narducci F, Fastrez M, Ponce J, et al. Robotically assisted para-aortic lymphadenectomy: surgical results: a cohort study of 487 patients. Int J Gynecol Cancer. 2015;25(3):504-11.

4. Missana MC, Pomel C. Endoscopic latissimus dorsi flap harvesting. Am J Surg. 2007;194(2):164-9.

5. Dejode M, Barranger E. Endoscopic 3D latissimus dorsi flap harvesting for immediate breast reconstruction. Gynecol Obstet Fertil. 2016;44(6):372-4

6. Iglesias M, Gonzalez-Chapa DR. Endoscopic latissimus dorsi muscle flap for breast reconstruction after skin-sparing total mastectomy: report of 14 cases. Aesthet Plast Surg. 2013;37(4):719-27.

7. Xu S, Tang P, Chen X, Yang X, Pan Q, Gui Y, Chen L. Novel technique for laparoscopic harvesting of latissimus dorsi flap with prosthesis implantation for breast reconstruction: a preliminary study with 2 case reports. Medicine (Baltimore). 2016;95(46):e5428.

8. Nakajima H, Fujiwara I, Mizuta N, Sakaguchi K, Ohashi M, Nishiyama A, et al. Clinical outcomes of video-assisted skin-sparing partial mastectomy for breast cancer and immediate reconstruction with latissimus dorsi muscle flap as breast-conserving therapy. World J Surg. 2010;34(9):2197-203.

9. Yuan $H$, Xie D, Xiao X, Huang $X$. The clinical application of mastectomy with single incision followed by immediate laparoscopic-assisted breast reconstruction with latissimus dorsi muscle flap. Surg Innov. 2017;24(4):34952. https://doi.org/10.1177/1553350617702309 Epub 2017 Apr 11.

10. Selber JC, Baumann DP, Holsinger FC. Robotic latissimus dorsi muscle harvest: a case series. Plast Reconstr Surg. 2012;129(6):1305-12.

11. Selber JC, Baumann DP, Holsinger CF. Robotic harvest of the latissimus dorsi muscle: laboratory and clinical experience. J Reconstr Microsurg. 2012;28: 457-64.

12. Chung JH, You HJ, Kim HS, Lee Bl, Park SH, Yoon ES. A novel technique for robot assisted latissimus dorsi flap harvest. J Plast Reconstr Aesthet Surg. 2015;68(7):966-72.

13. Clemens MW, Kronowitz S, Selber JC. Robotic-assisted latissimus dorsi harvest in delayed-immediate breast reconstruction. Semin Plast Surg. 2014; 28(1):20-5.

14. Pacelli J, Sharifzadehgan S, Rua S, Houvenaeghel G, Ngo C, Bats AS, Lécuru F, Delomenie M. Robotic-assisted latissimus dorsi muscle harvest for immediate breast reconstruction. Gynecol Obstet Fertil Senol. 2018;46(1011):744-6.

15. Dejode $M$, Barranger E. Endoscopic $3 D$ latissimus dorsi flap harvesting for immediate breast reconstruction. Gynecol Obst \& Fertil. 2016:44:368-74

16. Dauplat J, Kwiatkowski F, Rouanet P, Delay E, Clough K, Verhaeghe JL, Raoust I, Houvenaeghel G, Lemasurier P, Thivat E, Pomel C, STIC-RMI working group. Quality of life after mastectomy with or without immediate breast reconstruction. Br J Surg. 2017;104(9):1197-206.

17. Dindo D, Demartines N, Clavien PA. Classification of surgical complications: a new proposal with evaluation in a cohort of 6336 patients and results of a survey. Ann Surg. 2004:240:205-13.

18. Lin CH, Wei FC, Levin LS, Chen MC. Donor-site morbidity comparison between endoscopically assisted and traditional harvest of free latissimus dorsi muscle flap. Plast Reconstr Surg. 1999;104(4):1070-7.

19. Zinzindohoué C, Bertrand P, Michel A, Monrigal E, Miramand B, Sterckers N, et al. A prospective study on skin-sparing mastectomy for immediate breast reconstruction with latissimus dorsi flap after neoadjuvant chemotherapy and radiotherapy in invasive breast carcinoma. Ann Surg Oncol. 2016;23(7): 2350-6.

20. Barrou J, Bannier M, Cohen M, Lambaudie E, Gonçalves A, Bertrand P, et al Pathological complete response in invasive breast cancer treated by skin sparing mastectomy and immediate reconstruction following neoadjuvant chemotherapy and radiation therapy: comparison between immunohistochemical subtypes. Breast. 2017:32:37-43.

21. Paillocher N, Florczak AS, Richard M, Classe JM, Oger AS, Raro P, et al. Evaluation of mastectomy with immediate autologous latissimus dorsi breast reconstruction following neoadjuvant chemotherapy and radiation therapy: a single institution study of 111 cases of invasive breast carcinoma. Eur J Surg Oncol. 2016:42(7):949-55

22. Dikmans RE, Negenborn VL, Bouman MB, et al. Two-stage implant-based breast reconstruction compared with immediate one-stage implant-based breast reconstruction augmented with an acellular dermal matrix: an openlabel, phase 4, multicentre, randomised, controlled trial. Lancet Oncol. 2017; 18(2):251-8.

\section{Publisher's Note}

Springer Nature remains neutral with regard to jurisdictional claims in published maps and institutional affiliations.

Ready to submit your research? Choose BMC and benefit from:

- fast, convenient online submission

- thorough peer review by experienced researchers in your field

- rapid publication on acceptance

- support for research data, including large and complex data types

- gold Open Access which fosters wider collaboration and increased citations

- maximum visibility for your research: over $100 \mathrm{M}$ website views per year

At BMC, research is always in progress.

Learn more biomedcentral.com/submissions 